\title{
An Investigation on People's Perception of the Otaku Subculture in China
}

\author{
Danzeng Dedan ${ }^{1, *}$ \\ ${ }^{1}$ Department of Japanese, Xiamen University of Technology, Xiamen, Fujian 361024, China \\ * Danzeng Dedan. Email: zwtribenliuxue@163.com
}

\begin{abstract}
Originated from Japan, the Otaku subculture describes one's tendency to stay at home and avoid social interactions as much as possible. In recent years, the Otaku subculture becomes increasingly popular in China, yet little is known about how the general population perceives the followers of the Otaku subculture. In the current study, we made the first attempt to investigate people's perception of the Otaku subculture with a mixed-method approach that combines a qualitative analysis and a quantitative analysis. We found that the three most defining features of the Otaku subculture are (1) depending largely on the internet, (2) unwillingness to engage in social interactions, and (3) a void of stable jobs and studies. Furthermore, among the three features, the second one was voted as the one that is most predictive ford one's perception of the general level of happiness on the active followers of the Otaku subculture. We discussed the practical relevance of the current study as well as important directions for future research.
\end{abstract}

\section{Keywords: The otaku subculture, person perception}

\section{INTRODUCTION}

Originated in Japan, the term Otaku describes a group of people who fully devote themselves to animations and games so much so that they ignore other aspects of life [7]. It was first officially used by the famous Japanese cartoonist Akio Nakamori in the article "Research on Otaku" serialized in "Manga Berry" from June 1983 to December 1983. Later on, the exact meaning of Otaku expanded and the term was also used to characterize those who constantly stay at home, indulge in their personal hobbies, and minimize their social interactions [14]. With the transition of the meaning of Otaku, It develops into a sub-culture that appears on the premise of the modern political situation and consumer culture [8]. Furthermore, the concept and practice of the Otaku subculture had its influence thrive far beyond its birthplace Japan and spread into its neighboring countries, such as China and Korea [6] and also countries all over the world.

In China, the emerging subculture of Otaku becomes an important social phenomenon and attracts a large group of teenagers to closely follow its prominent lifestyle that encourages young teenagers to stay at home and avoid offline social interactions [11]. Although aligned with the subculture of Otaku allows one to fully enjoy the freedom of watching favorite movies and animations, a full deprivation of social interactions could also bring about physical and mental health concerns. For example, reports from China Youth Daily (2019) have blamed the ever-increasing rate of psychological problems among college students on their lack of offline social interactions and group activities. As such, in Chinese society, the perceptions of the Otaku subculture are mixed among the general population: while people are praised for the independence and freedom inherited in the subculture, people also worry about the negative consequences of being isolated for those who adopt the lifestyle promoted by the Otaku subculture.

As the Otaku subculture continuously expands and its influence and its impacts on one's physical and mental health are considered heterogeneous, it is of vital importance to investigate the social environment that cultivates the Otaku subculture as well as how the society as a whole perceives those who are closely committed to the Otaku subculture. To our knowledge, however, all of the studies to date exclusively examined the Otaku subculture from the cultural lens but leave it unknown with respect to the perceptions of this subculture. In the current research, our primary objective is to fill this research gap by (1) identifying a series of most crucial characteristics that are considered as defining features of the Otaku subculture, and (2) evaluating to what extent people believe the ones that follow the Otaku subculture 
are happy and examining possible antecedents of such happiness perceptions. To offer comprehensive and concise answers to these two questions, the current study adopts a mixed-method approach that combines both qualitative and quantitative analyses.

The remaining of the article will be organized as follows. First, we explain social mechanisms that possibly underlie people's perception of the Otaku subculture. In the second section, a qualitative analysis is reported in which ten major features of the Otaku subculture have been identified with extensive and detailed interviews. Then, a quantitative analysis is reported where we conducted a survey study to investigate whether the general population considered those that follow the Otaku subculture as happy persons and the series of predictors of these perceptions. Last, we discuss the limitations of the current research as well as possible directions for future research.

\subsection{Social mechanisms that underlie one's perception of the Otaku subculture}

A clear, concise, and unambiguous perception of the Otaku subculture could be traced back to its origins. The perception of the Otaku subculture was initially very positive in Japan. It was born in the golden age of the economy: in the 1980s, Japan's economy was developing rapidly and people's living standards have been improving substantially [10]. The prosperities of the economic world tolerate or even encourage slight deviations from the social norm and people were tired of repetitions of Japanese manga animation [12]. As a consequence, many people - especially the young - were fascinated by the Otaku animations and viewed the Otaku subculture as an effective way to rebel as well as to cope with political, social, and psychological stress. However, not long after this initial honeymoon period, the rebellious nature of the Otaku subculture and its strong deviation from social norms started to receiving strong objections from Japanese citizens, especially with recessions in the economic conditions since 1986 [9]. Japanese culture has been regarded as one of the representatives of the tight culture [4], meaning that in general people may have little tolerance for individuals who deviate from the social norms. Because people who followed the Otaku subculture tend to symbolize their identity with specific symbols on the shirts or pants, they might appear to be very different compared with the general appearance and therefore were viewed as strangers by the general Japanese population. Worse still, an incident - called the Miyazaki Tsunami incident occurred in the second half of the 1980s and has changed the image of the Otaku subculture fundamentally. In the incident, a young man killed a large number of young people. When the police searched the home, they found a large number of animated videotapes that are closely related to the Otaku subculture. This offered the media an eye-catching story to report and resonate with the public's generally negative perception of the Otaku subculture. Since then, the Otaku subculture has been linked with criminal thoughts and behaviors. Although with the popularization of the Otaku subculture, the vast majority of Japanese citizens have realized their misunderstanding of the Otaku subculture, there are still many Japanese who believe that the Otaku subculture is evil and should be eliminated and that people who are into the Otaku subculture are the most strange person [13]. Furthermore, this negative stereotype is enhanced by the appearance of a small group of Otaku lovers: because they typically stay at home all day, they sometimes appear nasty with unbearable smells. The general population, therefore, tends to avoid this group because of the fear of disease [1].

Turning the lens to China, the Otaku subculture has to turn into a broad concept that, as we pointed out earlier in the article, consists of people that tend to stay at home all day and avoid any non-essential outings or social interactions. This group of people is typically introverted who do not enjoy offline communications and who always find much more excitement with themselves instead of being with friends [15]. Interestingly, as the new generation of Chinese enjoys a greater extent of economic and social freedom, it could be observed that the amount of people who follow the lifestyle of the Otaku subculture has increased dramatically in recent years [16].

Unlike Japan, the vast majority of followers of the Otaku subculture have stable studies or jobs in China [15]. Consequently, they are fascinated by the Otaku subculture not because of a general tendency to be rebellious or avoid the outside world, but because of personal preferences to minimize social contact. Despite this important feature, the general population in China still regards the Otaku subculture as a strange one because of the large disagreement with the mainstream culture that advocates being social and being proactive. Importantly, like Japan, China is also a country with very tight cultural value and generally does not tolerate large deviation from the social norm. Therefore, people tend to hold a negative stereotype of those who follow the lifestyle of the Otaku subculture. Moreover, they think the subgroup that is into the Otaku subculture is generally very well connected because of the shared core value.

\section{INTERVIEWS AND A QUALITATIVE ANALYSIS}

The objective of the qualitative study is to identify a series of most crucial characteristics that are considered as defining features of the Otaku subculture. This series of defining features will be used as a starting point for the quantitative analysis reported below. 


\subsection{Method}

We have conducted interviews with a total of six participants. The participants were selected according to the following criteria: (1) they do not follow the Otaku subculture themselves 2) they understand the broad concept of the Otaku subculture in the Chinese context. The participants were recruited from social media Wechat. According to the method of sociological investigation, the interview outline was drawn up in the form of a personal semi-structured interview. The final interview outline was then formally modified by an expert in the field. The duration of the interviews was between 15-30 mins.

\subsection{Results}

We extracted the answers with a coding scheme and summarized these answers with the text analysis. We have found the following 10 characteristics were mostly mentioned as defining characteristics of the group of the people that closely follow the Otaku subculture:

1. Obsessed with something

2. Rely on the Internet and electronics

3. Don't want to go to work/school

4. Unstable schedule

5. Rarely go out or refuse to go out

6. Don't like to meet people that they have not met before

7. They have two sides to personality

8. They don't like communication and have a great affection for virtual characters

\section{They are mostly overweight}

10. Most of them do not engage in close relationships.

Among the above 10 characteristics, the three most noticed ones are $\mathrm{Nr} .2$ relying on the internet and electronics, Nr.6 they do not like to meet with people that we have not met before, and Nr. 4 they do not have a stable schedule for jobs or studies.

\section{SURVEYS AND A QUANTITATIVE ANALYSIS}

The objective of the quantitative study is to evaluate to what extent people believe the ones that follow the Otaku subculture are happy and examining possible antecedents of such happiness perceptions.

\subsection{Method}

A total of 113 participants - recruited from Wechat have completed the survey. Among all of the participants, $15(13.3 \%)$ were male, $96(85.0 \%)$ were female, and 2
$(1.8 \%)$ were transgender. Most of the participants were aged between 18 to 21 . Table 1 offers an overview of participants' demographics.

Table 1 a descriptive analysis of participants' demographics

\begin{tabular}{|c|c|c|c|}
\hline \multirow{3}{*}{ Variables } & Categories & $\begin{array}{c}\text { Number of } \\
\text { participants }\end{array}$ & Percentage \\
\hline \multirow{3}{*}{ Gender } & Male & 15 & $13.27 \%$ \\
\cline { 2 - 4 } & Female & 96 & $84.96 \%$ \\
\cline { 2 - 4 } & Transgender & 2 & $1.77 \%$ \\
\hline \multirow{6}{*}{ Age } & 14 & 1 & $0.88 \%$ \\
\cline { 2 - 4 } & 15 & 1 & $0.88 \%$ \\
\cline { 2 - 4 } & 16 & 2 & $1.77 \%$ \\
\cline { 2 - 4 } & 17 & 9 & $7.96 \%$ \\
\cline { 2 - 4 } & 18 & 12 & $10.62 \%$ \\
\cline { 2 - 4 } & 19 & 13 & $11.50 \%$ \\
\cline { 2 - 4 } & 20 & 23 & $27.43 \%$ \\
\cline { 2 - 4 } & 21 & 7 & $20.35 \%$ \\
\cline { 2 - 4 } & 22 & 2 & $6.19 \%$ \\
\cline { 2 - 4 } & 23 & 5 & $1.77 \%$ \\
\hline & Above 24 & 4 & $3.42 \%$ \\
\hline
\end{tabular}

The participants were instructed to evaluate to what extent they consider the people that closely follow the Otaku subculture in China (1) depend largely on the internet, (2) do not want to socialize with other people, (3) do not have stable jobs or studies, and (4) are generally happy. Note that the first three questions cover the three most important characteristics identified in the qualitative analysis as the most important defining features of the group of people who closely follow the Otaku subculture. For each question, the partitions were asked to evaluate on a 10-point Likert scale, ranging from (1) totally disagree to (10) totally agree.

In the current analysis, we first used a correlational analysis to evaluate the bivariate relationships of variables that offer initial insights into the research question under consideration. After that, a regression analysis was carried out to determine the most important predictors of people's evaluation of the level of happiness of these people that follow the Otaku subculture.

\subsection{Results}

The means and standard deviations of all variables as well as the correlations between variables are presented in Table 2.

Table 2 Means, standard deviations of all variables and correlations between each pair of variables

\begin{tabular}{|c|l|l|l|l|l|}
\hline Variable & M & SD & $\mathbf{1}$ & $\mathbf{2}$ & $\mathbf{3}$ \\
\hline $\begin{array}{c}\text { 1. } \\
\text { Depende } \\
\text { nce on } \\
\text { the } \\
\text { internet }\end{array}$ & 8.48 & 1.63 & $.35^{* *}$ & & \\
\hline $\begin{array}{c}2 . \text { Avoid } \\
\text { social } \\
\text { interactio } \\
\text { ns }\end{array}$ & 6.23 & 2.49 & & & \\
\hline & 8.14 & 1.57 & $.51^{* *}$ & $.40^{* *}$ & \\
\hline $\begin{array}{c}3 . \\
\text { Without }\end{array}$ & & & {$[.18, .50]$} & & \\
\hline
\end{tabular}




\begin{tabular}{|c|r|r|r|r|r|}
\hline $\begin{array}{c}\text { stable } \\
\text { jobs or } \\
\text { studies }\end{array}$ & & & & & \\
\hline & & & {$[.35, .63]$} & {$[.23, .54]$} & \\
\hline $\begin{array}{c}4 . \\
\text { General } \\
\text { level of } \\
\text { happines } \\
\mathrm{S}\end{array}$ & 7.28 & 2.26 & .15 & $.23^{*}$ & .15 \\
\hline & & & $\begin{array}{r}{[-.04,} \\
.33]\end{array}$ & {$[.04, .40]$} & $\begin{array}{r}{[-.04,} \\
.32]\end{array}$ \\
\hline
\end{tabular}

Note. $\mathrm{M}$ and SD are referred to as mean and standard deviation, respectively. $* \mathrm{p}<.05 . * * \mathrm{p}<.01$.

From Table 2, we noted that the average level of happiness was $7.28(\mathrm{SD}=2.26)$, indicating that a large number of people think the people that follow the Otaku subculture are generally happy. This contradicts with previous research as all of the previous studies suggest a negative stereotype towards the group of people that follow the Otaku subculture. More interestingly, we also found the average level of happiness was positively associated with the extent people believe those following the Otaku subculture avoid social interactions as much as possible $(\mathrm{r}=.23, \mathrm{p}<.05)$. This relationship was further examined in the regression analysis.

In the regression analysis, we tested whether people's perceptions of the three most defining features of the Otaku subculture are important predictors of people's perception of the general level of happiness for those who endorse the Otaku subculture. The results of the regression analysis were reported in Table 3.

From Table 3, we found none of the three predictors are significantly correlated with one's perception of the general happiness level of the people who endorse the Otaku subculture at a significant level of 5\%. However, the feature of avoid social interactions appeared to be marginally correlated with the dependent variable $(b=$ $.17, \mathrm{p}<.1)$.

Table 3 The results of the regression analysis

\begin{tabular}{|c|c|c|c|c|}
\hline Predictor & $b$ & $\begin{array}{c}b \\
95 \% \mathrm{Cl}\end{array}$ & $r$ & Fit \\
\hline (Intercept) & $5.00^{* *}$ & $\begin{array}{r}\text { [2.45, } \\
7.55] \\
\end{array}$ & & \\
\hline $\begin{array}{c}\text { Dependence on } \\
\text { the internet }\end{array}$ & 0.09 & $\begin{array}{r}{[-0.22} \\
0.39]\end{array}$ & .15 & \\
\hline $\begin{array}{l}\text { Avoid social } \\
\text { interactions }\end{array}$ & 0.17 & $\begin{array}{r}{[-0.01} \\
0.36] \\
\end{array}$ & $.23^{*}$ & \\
\hline $\begin{array}{c}\text { Without stable jobs } \\
\text { or studies }\end{array}$ & 0.06 & $\begin{array}{r}-0.26 \\
0.38]\end{array}$ & .15 & \\
\hline & & & & $\begin{array}{l}R^{2}= \\
.059\end{array}$ \\
\hline
\end{tabular}

\section{CONCLUSION}

The Otaku subculture originates from Japanese animations and features staying at home all day without many social interactions. It has attracted a large number of followers - most of them are adolescents or young adults - in recent years in China and other Asian countries. Despite its increasing popularity, little is known about the social and behavioral consequences of following the Otaku subculture as well as how the general population perceives the followers of the Otaku subculture. The current study serves as a novel attempt that aims to entangle what are considered as the most important defining features of the Otaku subculture and how these features affect people's perception of the general level of happiness concerning the followers of the Otaku subculture. The results of the qualitative study have suggested the three most important characteristics of the Otaku subculture are (1) depending largely on the internet, (2) unwillingness to engage in social interactions, and (3) a void of stable jobs and studies. Moreover, our quantitative analysis has revealed that the second characteristic of the Otaku subculture is considered to be the most decisive factor that affects one's perception of the general level of happiness on the active followers of the Otaku subculture.

The results of the current study shed important light on our understanding of the Otaku subculture. Although, as reported in the introduction, previous studies have consistently demonstrated negative stereotypes towards the Otaku subculture, the current study depicts a contradictory picture. One of the reasons for this conflict is that the participants of the current study are relatively younger than previous studies and are therefore more likely to appreciate the freedom advocated by the Otaku subculture as well as its close connections to Japanese animations. Another plausible explanation is that the popularity of the Otaku subculture has increased so dramatically that people have turned positive to it.

We point out several directions for future research. First, to better understand the developments of the Otaku subculture in the Chinese context, longitudinal studies that collect data from multiple occasions are important and could potentially offer important insights into the trajectories of the developments of the Otaku subculture. Second, comparative studies are also of great interest for the researchers who would like to understand cultural differences in the Otaku subculture. As we argued in the current study, the concept and the meaning of the Otaku subculture may differ substantially in different countries. Therefore, such a comparative study may offer important information with respect to these differences in various countries. Last, for personality psychologists, it might be interesting to investigate the personality antecedents of one's endorsement of the Otaku subculture.

\section{REFERENCES}

[1] Ackerman, J. M., Hill, S. E., \& Murray, D. R. (2018). The behavioral immune system: Current concerns and future directions. Social and Personality Psychology Compass, 12(2), e12371.

[2] Chien, S. S. (2010). Economic freedom and political control in post-Mao China: A perspective of upward accountability and asymmetric 
decentralization. Asian Journal of Political Science, 18(1), 69-89.

[3] Dong, Y., Yin, M., Zhang, Q., \& Chen, T. (2018, March). A Study on the Situation and Behavioral Characteristics of" Homebody" of Undergraduates. In 2nd International Conference on Culture, Education and Economic Development of Modern Society (ICCESE 2018) (pp. 1084-1088). Atlantis Press.

[4] Gelfand, M. J., Nishii, L. H., \& Raver, J. L. (2006). On the nature and importance of cultural tightnesslooseness. Journal of Applied Psychology, 91(6), 1225.

[5] Jie, Z. (2011). Psychological Inquiry about" Otaku culture" in college student. Science of Social Psychology, Z1.

[6] Jing, Q., \& Ruiming, L. (2013). New trends among young Chinese consumers. SERI Quarterly, 6(1), 23.

[7] Kinsella, S. (1998). Japanese subculture in the 1990s: Otaku and the amateur manga movement. Journal of Japanese Studies, 289-316.

[8] Kitabayashi, K. (2004). The Otaku group from a business perspective: Revaluation of enthusiastic consumers. NRI Papers, 84(1), 1-10.

[9] Kondo, N., Subramanian, S. V., Kawachi, I., Takeda, Y., \& Yamagata, Z. (2008). Economic recession and health inequalities in Japan: analysis with a national sample, 1986-2001. Journal of Epidemiology \& Community Health, 62(10), 869-875.

[10] Kuznets, P. W. (1988). An east Asian model of economic development: Japan, Taiwan, and South Korea. Economic development and cultural change, 36(S3), S11-S43.

[11] Louie, K. (2012). Popular culture and masculinity ideals in East Asia, with special reference to China. The Journal of Asian Studies, 71(4), 929943.

[12] MacWilliams, M. W. (2014). Japanese visual culture: explorations in the world of manga and anime. Routledge.

[13] Miho, A. (2015). The Construction of Discourses on Otaku: The History of Subcultures from 1983 to 20051. Debating Otaku in Contemporary Japan: Historical Perspectives and New Horizons, 105.

[14] Niu, H. J., Chiang, Y. S., \& Tsai, H. T. (2012). An exploratory study of the otaku adolescent consumer. Psychology \& Marketing, 29(10), 712725 .
[15] Yang, Q. (2012). The relationship of psychological resilience, self-supporting personality and psychological health of stay-at-home college students. Chinese Journal of Behavioral Medicine and Brain Science, 21(3), 268-271.

[16] Yueh, H. I. S. (2019). From Japanese otaku to Taiwanese zhainan: Understanding transcultural masculinity through a cultural term in Taiwan. Journal of International and Intercultural Communication, 12(2), 111-127. 